\title{
The Role of DDB2 in Regulating Cell Survival and Apoptosis Following DNA Damage - A Mini-Review
}

\author{
Chuck C.-K. Chao \\ Department of Biochemistry and Molecular Biology \\ Graduate Institute of Biomedical Sciences, Chang Gung University, Taiwan \\ Republic of China
}

\section{Introduction}

Nucleotide excision repair (NER) represents a central cellular process for the removal of structurally and chemically diverse DNA lesions [Friedberg et al., 2006]. Mutations in genes involved in NER are associated with rare autosomal recessive syndromes such as xeroderma pigmentosum (XP), a condition characterized by sensitivity to UV light, neurological abnormalities, and a propensity to develop skin cancer (Cleaver, 2005). The observation that cells from XP subgroup E (XP-E cells XP2RO and XP3RO) are defective in recognizing damaged DNA and performing NER highlighted the physiological importance of the protein termed DNA damage-binding protein, or DDB [Chu \& Chang, 1988]. The DDB protein, sometimes also referred to as UV-DDB due to its high affinity and specificity for UV-damaged DNA, contains two principal subunits, DDB1 and DDB2 [Grossman, 1976; Keeney et al., 1993; Takao et al., 1993]. The DDB protein complex also binds to non-UVdamaged DNA, like cisplatin-modified DNA, although with much lower affinity. Although the history of DDB spans more than two decades, the complete understanding of its physiological functions remains to be clarified. The activity of DDB has been repeatedly described in crude mammalian cell extracts by electrophoretic mobility shift assays or filterbinding assays performed by different laboratories since the first report of its discovery [Feldberg \& Grossman, 1976]. Notably, micro-injections of DDB complexes into the nucleus of XP-E cells restored NER activity [Keeney et al., 1994], supporting the notion that DDB participates in chromatin NER. The DDB1 gene from simian cells was the first $D D B$ gene to be identified [Takao et al., 1993]. The human DDB1 and DDB2 genes were subsequently sequenced [Dualan et al., 1995; Lee et al., 1995]. Soon after, DNA sequencing from Linn's laboratory revealed that DDB2 is mutated in XP-E cells which lack DDB activity [Nichols et al., 1996; Tang \& Chu, 2002]. The predicted DDB2 protein sequence was shown to contain several functional domains, including WD40 repeats, post-translation modification sites (e.g. acetylation, phosphorylation, and ubiquitination), DDB1- and DNA-binding sites, as well as a DWD box. Notably, in a majority of XP-E cell lines, DDB2 was found to be altered at domains other than the one required for binding DNA. Thus, DDB appears to be regulated at several levels in UV-irradiated cells, including by transcriptional activation of DDB2 mRNA, post-translational modification, translocation to the nucleus, complex formation, 
and proteolytic degradation of DDB2 protein through ubiquitination [for a recent review, see Sugasawa, 2010]. Notably, 60\% of chromatin-bound DDB2 is degraded within $4 \mathrm{hrs}$ of UV irradiation. After 48 hrs, DDB2 mRNA levels increase several fold above the level seen in non-irradiated cells [Nichols et al., 2000; Rapic-Otrin et al., 2002]. Interestingly, the majority of UV-induced DNA photoproducts in human cells are repaired by this time [Mitchell et al., 1985].

\section{DDB2 recognizes DNA damage during global genome NER}

NER removes diverse DNA lesions, ranging from UV-induced cyclobutane pyrimidine dimers (CPD) and 6-4 pyrimidine-pyrimidone photoproducts (6-4PP) to a variety of bulky adducts formed by environmental carcinogens. Mammalian NER comprises global genome NER (GGNER) and transcription-coupled NER (TC-NER). These two processes involve similar but distinct repair proteins that process DNA damage and chromatin proteins like histones may significantly regulate the activity of repair proteins (reviewed by Friedberg et al., 2006). One such multiprotein complex involved in GG-NER and containing both DDB1 and DDB2 is closely related to a complex containing DDB1 and the Cockayne syndrome group A (CSA) protein in TC-NER. In GG-NER, DNA is initially surveyed for lesions by XP group C (XPC) protein-RAD23B (Sugasawa et al., 1998) and the UV-DDB complex (Fitch et al., 2003; Moser et al., 2005; Sugasawa et al., 2005). DDB2 binds to DDB1 to form the DDB complex which may recognize UV-induced DNA damage and recruit proteins of the NER pathway to initiate GGNER (Hwang et al., 1999; Tang et al., 2000). The DDB complex preferentially binds to UVinduced CPD, 6-4PP, apurinic sites, and short mismatches (Fujiwara et al., 1999; Kulaksiz et al., 2005; Sugasawa et al., 2005; Wittschieben et al., 2005). While XPC functions as a versatile factor that senses abnormal DNA structures, DDB appears to recognize more specific types of lesions, particularly UV-induced 6-4PP, whereas binding to CPD is much weaker but nonetheless detectable [Payne \& Chu, 1994]. Strikingly, structural analysis of DDB bound to DNA duplex containing 6-4PP has revealed that the DDB2 subunit is responsible for the interaction, and this subunit induces the movement of the two affected bases into a binding pocket, therefore indicating that $\mathrm{DDB}$ has evolved to specifically recognize dinucleotide lesions, like UV photolesions [Figure 1; Scrima et al., 2008]. Furthermore, accumulating evidence has confirmed the existence of multiple forms of DDB2 mRNA splicing variants, including isoforms D1 and D2, which do not interact with DDB1, but inhibit UV-damaged DNA repair (Inoki et al., 2004). DDB2 is ubiquitously expressed in human tissues, with the highest level being found in corneal endothelium and the lowest level in the brain. Isoform D1 is highly expressed in brain and heart tissues, whereas isoforms D2, D3, and D4 are weakly expressed in these tissues (Inoki et al., 2004). Interestingly, repair of DNA damage induced by UV light appears to be less active in brain and heart tissues which are naturally protected against UV irradiation and express high levels of isoform D1.

\section{DDB2 links DNA repair to protein ubiquitination}

Another breakthrough that links protein ubiquitination with GG-NER is the finding that DDB is part of an ubiquitin ligase (E3) complex. Epitope-tagged DDB2 purified from cells was found in complex with CUL4A, ROC1, DDB1, and the COP9 signalosome [Groisman et al., 2003]. Besides its function as part of the DDB-protein complex, DDB2 may function as a substrate-recognition module within the CUL4A ubiquitination complex. CUL4 is one of 


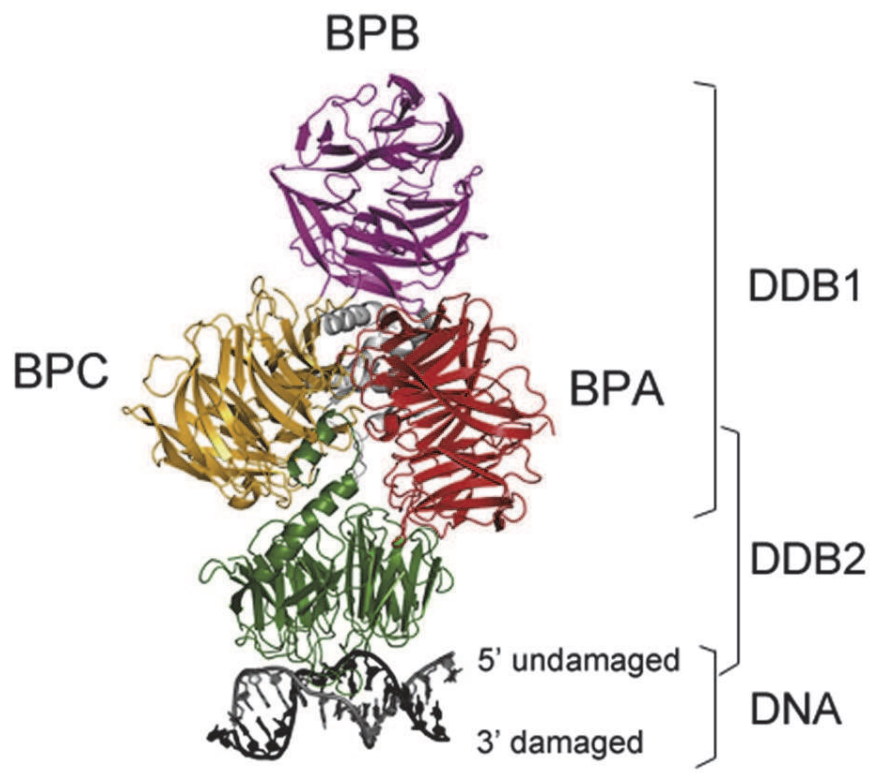

Fig. 1. Overall structure of the DDB1-DDB2-DNA complex. Ribbon representation of the DDB-DNA6-4PP complex: DDB2; DDB1-BPA; DDB1-BPB; DDB1-BPC; DDB1-CTD. The DNA6$4 \mathrm{PP}$ damaged and undamaged DNA strands are depicted in black and gray, respectively. DNA binding is carried out exclusively by the DDB2 subunit via its WD40 domain. The DDB1 structure consists of three WD40 $\beta$-propeller domains (BPA, BPB, and BPC) and a Cterminal helical domain (CTD, shown at the center). DDB2 binds to an interface between the DDB1 propellers BPA and BPC, where its helix-loop-helix motif inserts into a cavity formed by the two propellers. The structures reveal the molecular mechanism underlying highaffinity recognition of UV lesions (damaged DNA strand) that are refractory to detection by $\mathrm{XPC}$. The structures also suggest a mechanism for the assembly of the DDB-CUL4 ubiquitin ligase in chromatin and provide a framework for understanding the ubiquitination of proteins proximal to damage sites. [For detail, see Scrima et al., 2008].

three founding cullins that are conserved from yeast to humans. A large number of E3 ubiquitin-protein ligase complexes are part of the DCX proteins (short for DDB1-CUL4-Xbox). Components of the CUL4-DDB-ROC1 (also known as CUL4-DDB-RBX1) include CUL4A or CUL4B, DDB1, DDB2, and RBX1 (Chen et al., 2001; Groisman et al., 2003). Other CUL4-DDB-ROC1 complexes may also exist in which DDB2 is replaced by a subunit that targets an alternative substrate. These targeting subunits are generally known as DCAF proteins (short for DDB1- and CUL4-associated factor) or CDW (short for CUL4-DDB1associated WD40-repeat; for reviews, see Lee \& Zhou, 2007; Jackson \& Xiong, 2009; Sugasawa, 2009). Many CUL4 complexes are involved in chromatin regulation and are frequently hijacked by viruses (reviewed by Jackson \& Xiong, 2009). The DDB1-CUL4-ROC1 complex may ubiquitinate histones $\mathrm{H} 2 \mathrm{~A}, \mathrm{H} 3$, and $\mathrm{H} 4$ at sites of UV-induced DNA damage (Wang et al., 2006; Kapetanaki et al., 2006; Guerrero-Santoro et al., 2008). The ubiquitination of histones may facilitate their removal from the nucleosome and promote assembly of NER components for subsequent DNA repair. Furthermore, the DDB1-CUL4-ROC1 complex 
ubiquitinates XPC and DDB2, which may enhance DNA binding by XPC and promote NER (El-Mahdy et al., 2006; Sugasawa et al., 2005). Structural analysis support the notion that CUL4 uses DDB1 as a large $\beta$-propeller protein and as a linker to interact with a subset of WD40 proteins like DDB2, which serves as substrate receptors, forming as many as 90 E3 complexes in mammals [Jackson \& Xiong, 2009]. Taken together, these results indicate that DDB complex is a component of the CUL4A-based ubiquitin ligase DDB1-CUL4ADDB2, and that DDB2 may coordinate the ubiquitination of various proteins at DNA damage sites during GG-NER.

In addition, CUL4B also binds to UV-damaged chromatin as a part of the DDB1-CUL4BDDB2 E3 ligase in the presence of functional DDB2. Nevertheless, CUL4B is localized in the nucleus and facilitates the transfer of DDB1 into the nucleus independently of DDB2 [Guerrero-Santoro et al., 2008]. Notably, DDB1-CUL4BDDB2 is more efficient than DDB1CUL4ADDB2 in mono-ubiquitinating histone H2A in vitro, suggesting that the DDB1CUL4BDDB2 $\mathrm{E} 3$ ligase may have a distinctive function in modifying the chromatin structure at sites of UV lesions and promoting efficient GG-NER. Intriguingly, the CSA protein, a WD40 motif protein defective in a complementation group of Cockayne's syndrome, forms a similar E3 complex in place of DDB2 at damage sites during TC-NER. Although not detected in the DDB2 and CSA complex, CUL4B is highly expressed in mammalian cells, and the two CUL4 isoforms CUL4A and CUL4B appear to be redundant, at least for some cellular functions [Higa et al., 2003; Hu et al., 2004].

\section{DDB2 inhibits apoptosis in cultured cell lines and Drosophila}

Although the regulation of the DDB2 gene is complex, evidence on the biological function of DDB2 in response to apoptotic stimuli has accumulated. Evidence from biochemical experiments has shown how DDB2 interacts with proteins, DNAs, and RNAs. Most strikingly, structural studies using X-ray crystallography support the evidence of biochemical studies, as seen for example with GG-NER. Nevertheless, a complete understanding of the biological roles of DDB2 remains to be fully elucidated. To assess this question, we explored the role of DDB2 in regulating UV sensitivity in both human cells and Drosophila [Sun et al., 2010]. As such, a full-length DDB2 open reading frame sequence was overexpressed in cells that express low or no DDB2. Conversely, DDB2 expression was suppressed in cells that endogenously express high levels of DDB2 by stable expression of full-length anti-sense cDNA. Using this strategy, we found that DDB2 displays a protective role against UV irradiation and cell surface death receptor signaling in both cisplatin-selected human HeLa cells and hamster V79 cells [Sun et al., 2002a; Sun et al., 2002b; Sun \& Chao, 2005a]. Furthermore, cFLIP expression was upregulated by DDB2 in a dose- and time-dependent manner in HeLa cells, a process associated with inhibition of apoptosis [Sun \& Chao, 2005a]. Inhibition of cFLIP by anti-sense oligonucleotides substantially inhibited apoptosis induced by UV irradiation and death receptor signaling in HeLa and other cell lines. Importantly, the protective effect of DDB2 was only detected in cells in which cFLIP is elicited during apoptotic stimuli. In contrast, DDB2 did not show a protective effect against apoptotic stimuli in human cell lines in which cFLIP expression was not induced [Sun et al., 2010]. A transcription reporter assay also showed that DDB2 induces the transcription of cFLIP in a p38/MAPK-dependent manner [Sun \& Chao, 2005b], suggesting that the DDB2/cFLIP pathway may be active in specific cell conditions [Figure 2]. Surprisingly, overexpression of a DDB2 mutant (82TO) that does not significantly enhance DDB activity (Nichols et al., 1996), also protected HeLa cells from both UV- and Fas- 
induced cell death (Sun et al., 2002a; Sun \& Chao, 2005a), suggesting that the protection effect of DDB2 may be independent of its DNA repair activity. Furthermore, ectopic expression of human DDB2 in Drosophila dramatically reduced UV-induced animal death compared to control GFP expression. On the other hand, expression of DDB2 in Drosophila failed to rescue a different type of apoptosis induced by the genes reaper or eiger [Sun et al., 2010]. Depletion of DDB2 in HeLa cells did not affect apoptosis induced by cisplatin or mitomycin C (Sun et al., 2002a). In addition, overexpression or inhibition of DDB2 in HeLa cells only slightly affected cisplatin-induced caspase-8 signaling and apoptosis (Sun \& Chao, 2005a), probably due to the observation that cisplatin primarily induces mitochondrial apoptotic signaling (Gonzalez et al., 2001). These observations suggest that the modulation of apoptosis by DDB2 may be unique.

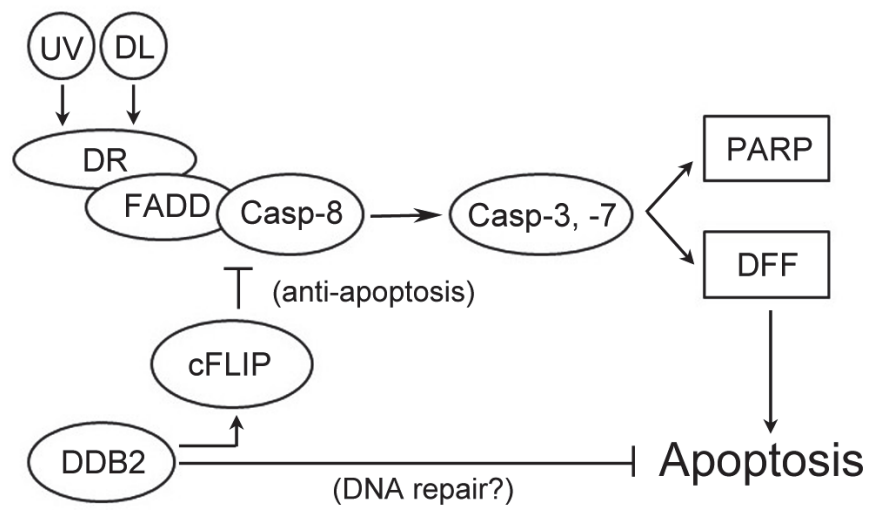

Fig. 2. Model illustrating the role of DDB2 in regulating non-DNA damage-induced apoptosis. An anti-apoptotic effect is proposed for DDB2 against death ligand- or UVinduced stress through cFLIP up-regulation. DDB2 transactivation of cFLIP is required to enhance their apoptosis-inhibitory function. UV- or death receptor-induced apoptosis is attenuated by the up-regulated cFLIP; consequently, activation of initiator caspases (3 and 7), cleavage of protein substrates (PARP and DFF), and apoptosis are inhibited. DDB2 may also attenuate UV-induced apoptosis through repair of DNA damage. However, evidence from protective DDB2 mutants suggests possible alternative pathways. DL, death ligands; DR, death receptors. [Modified from Sun and Chao, 2005a]

Cross-resistance to UV was found in cisplatin-selected cells, which overexpress DDB2 [Chu \& Chang, 1990; Chao et al., 1991]. DDB2 is a transcriptional partner of E2F1; however, the target of DDBs/E2F1 has not been identified (Hayes et al., 1998; Shiyanov et al., 1999). We found that the overexpression of DDB2 increases the expression of cFLIP at both the mRNA and protein levels in resistant cells in which DDB2 has been genetically suppressed [Sun and Chao, 2005a]. E2F1 was also shown to regulate the expression of cFLIP (Stanelle et al., 2002). Therefore, cFLIP may represent the first potential target of DDB2/E2F1. E2F1 promotes TNF-induced apoptosis by stabilizing the TRAF2 protein (Phillips et al., 1999). However, the possibility that DDB2/E2F1 may co-activate cFLIP expression suggests a possible dual role for E2F1 in regulating cell survival and death. Additional overexpression of E2F1 does not increase endogenous cFLIP expression more than overexpression of DDB2 alone (Peng, 2008). Thus, the increased level of E2F1 observed in resistant cells is not enough to support the apoptotic resistance mediated by DDB2-cFLIP. Although induction of cFLIP by DDB2 is required to 
protect cells against UV-induced apoptosis, at least in HeLa cells, we could not exclude the possibility that other genes are also involved in mediating the anti-apoptotic effect of DDB2.

\section{Ectopic expression of DDB2 induces apoptosis in DDB2-deficient cells}

An extensive review of XP-E and DDB has been presented by Itoh who focused on XP-E and DDB2 as well as the classification of photosensitive diseases [Itoh, 2006]. Surprisingly, XP-E cell strains proved to be abnormally resistant to UV irradiation and possessed reduced caspase-3 activity. Since the apoptotic defect in XP-E strains could be rescued by exogenous p53 expression, DDB2 was also proposed to regulate p53-mediated apoptotic pathway after UV irradiation in human primary cell strains [Itoh et al, 2000; 2003]. Cells from DDB2knockout mice also showed abnormal resistance and impaired p53 response to UV irradiation similar to human XP-E cell strains [Itoh et al., 2004]. Furthermore, a recent study has demonstrated that mouse embryonic fibroblasts and human HeLa that express DDB2 shRNA are resistant to apoptosis induced by a variety of DNA-damaging agents despite the activation of p53 and other pro-apoptotic genes [Stoyanova et al., 2009]. Also, these DDB2deficient cells are resistant to E2F1-induced apoptosis, probably due to the observation that these cells undergo p21Waf1/Cip1-associated cell cycle arrest following DNA damage. Notably, DDB2 targets p21Waf1/Cip1 for proteolysis and this process involves Mdm2 in a manner that is distinct from the p53-regulatory activity of Mdm2 [Stoyanova et al., 2009]. These results suggest a new regulatory loop involving DDB2, Mdm2, and p21Waf1/Cip1 that is critical in determining the cellular fate between apoptosis and cell cycle arrest (for DNA repair) in response to DNA damage. The existence of this regulatory loop may be strengthened by showing that forced expression of DDB2 renders XP-E or DDB2-deficient cells sensitive to apoptotic stimuli.

\section{Cancer-prone DDB2-deficient mice}

DDB2-knockout mice have been shown to be prone to cancer formation [Itoh et al., 2004]. Importantly, mice with single DDB2 allele knockout showed enhanced skin cancer following UV-B exposure, suggesting that DDB2 heterozygotes may be predisposed to skin cancer [Itoh et al., 2004]. In addition, XP mouse models were reported to be prone to the formation of papillomas induced by 7,12-dimethylbenz[a]anthracene (DMBA) [de Bohr et al., 1999; Nakane et al., 1995; de Vries et al., 1995], a carcinogen that produces bulky DNA adducts usually repaired by the NER system. On the other hand, p53-knockout mice are prone to spontaneous tumors [Donehower et al., 1992; Jacks et al., 1994], but not to tumors induced by DMBA or 12-O-tetradecanoyl-phorbol-13-acetate (TPA) [Kemp et al.,1993]. Taken together, these observations suggest that DDB2 may be involved in cancer formation through p53-mediated pathways. However, it is unclear whether re-introducing DDB2 in DDB2-knockout mice may prevent cancer formation.

\section{Concluding remarks and future perspectives}

The various results cited above suggest that the genetic integrity or gene expression status of the cells may be critical in determining the regulatory effects of DDB2 in response to apoptotic stimuli. The level of DDB2, p53, E2F1, and other proteins such as anti-apoptotic cFLIP and cell-cycle arrest p21, for instance, should be considered. The pro-apoptotic 
activity of p53 could vary between primary and cultured cell lines. For example, p53 activity in HeLa cells is hijacked by the human papillomavirus (HPV) E6 protein, a process that weakens apoptotic signaling in these cells. High levels of DDB2 may up-regulate and potentiate p53 activity by up-regulating apoptotic proteins in p53-normal cells. As such, HeLa cells, which harbor nearly null-p53 activity and additional anti-apoptotic cFLIP activity elicited by DDB2, may become resistant to apoptosis in response to cytotoxic DNA damage. These cellular responses are not surprising if the cultured cell lines were transformed by viruses or chemical means. Unfortunately, the cell lines used for the studies mentioned above are often treated this way. Furthermore, the expression of DDB2 isoforms, including the inhibitory D1 isoform, is often overlooked and the differential expression of such isoforms may dictate the cellular responses observed. Accordingly, alternative splicing of DDB2 transcripts and alteration of these genetic factors by other means in cell lines must be considered while evaluating the role of DDB2 in regulating apoptosis. In fact, there is no evidence so far that the apoptotic resistance of DDB2-defective XP-E, DDB2-knockout mouse cells, or DDB2-deficient human cells could be rescued by re-introducing DDB2 expression. In this sense, DDB2 is required to suppress apoptosis, but it does not suffice to be apoptotic. Furthermore, DDB2 as a proteasome component can target various proteins, such as p21 which is involved in cell cycle arrest, subsequently dysregulating cell cycle arrest during stress repair and leading to apoptosis. The cisplatin-selected HeLa cells used in our study do not display G1 arrest following mild, repairable DNA damage [Lin-Chao \& Chao, 1994], which may explain the negligible, pro-apoptotic influence of DDB2 found by others [Stoyanova et al., 2009]. Therefore, an updated model is proposed in Figure 3, in

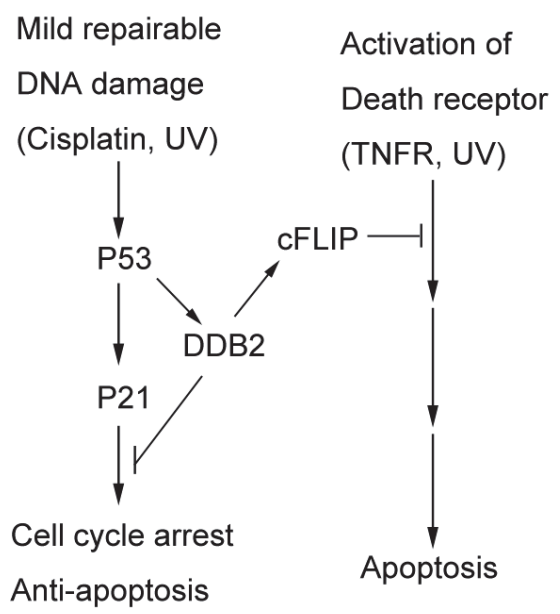

Fig. 3. Updated model for the regulation of DNA damage-induced apoptosis by DDB2. In this model, DNA damage applied to cells was mild and reached repairable level, leading to inhibition of apoptosis and cell cycle arrest for stress repair. The regulatory effect of DDB2 can be pro-apoptotic in cells experiencing mild DNA damage through p21 degradation which is targeted by DDB2. On the other hand, DDB2 can also be anti-apoptotic in cells harboring nonDNA damage apoptotic stimuli (e.g., death receptor) with up-regulation of anti-apoptotic cFLIP. Accordingly, the final outcome may be influenced by intrinsic mutations or extrinsic viral hijacking that can impair checkpoint for G1 arrest via p53 and p21. 
which the regulatory effect of DDB2 can be either pro-apoptotic in cells that respond to mild DNA damage or anti-apoptotic in cells that respond to non-DNA damage apoptotic stimuli and that show up-regulation of the anti-apototic cFLIP. Notably, we found that human DDB2 may play a protective role against UV irradiation in the fruit fly Drosophila which does not express DDB2 as seen in the DDB2-defective cultured cell models. Therefore, the seemingly contrasting results mentioned above may be explained by our models, and primary cell cultures which are more representative of in vivo situations may represent a better choice for future studies of the biological functions of DDB2.

\section{Acknowledgements}

The author would like to thank the members of his research group for helpful discussions. The author also appreciates the help of Jan Martel during preparation of the manuscript. This review is partly supported by the National Science Council (Taiwan), Chang Gung University, and the Foundation for the Advancement of Outstanding Scholarship.

\section{References}

de Bohr, J., van Steeg, H., Berg, R.J.W., Garssen, J., de Wit, J., van Oostrum, C.T.M., Beems, R.B., van der Horst, G.T., van Kreijl, C.F., de Gruijl, F.R., Bootsma, D., Hoeijmakers, J.H., Weeda, G. (1999). Mouse model for the DNA repair/basal transcription disorder trichothiodystrophy reveals cancer predisposition. Cancer Res., 59, 34893494

Chao, C.C., Huang, S.L., Huang, H.M., and Lin-Chao, S. (1991). Cross-resistance to UV radiation of a cisplatin-resistant human cell line: overexpression of cellular factors that recognize UV-modified DNA. Mol. Cell. Biol., 11, 2075-2080

Chen, X., Zhang, Y., Douglas, L., Zhou, P. (2001). UV-damaged DNA-binding proteins are targets of CUL-4A-mediated ubiquitination and degradation. J. Biol. Chem., 276, 48175-48182

Chu, G., Chang, E. (1988). Xeroderma pigmentosum group E cells lack a nuclear factor that binds to damaged DNA. Science, 242, 564-567

Chu, G., Chang, E. (1990). Cisplatin-resistant cells express increased levels of a factor that recognizes damaged DNA. Proc. Natl. Acad. Sci. USA, 87, 3324-3327

Cleaver, J.E. (2005) Cancer in xeroderma pigmentosum and related disorders of DNA repair. Nat Rev Cancer 5, 564-573

Donehower, L.A., Harvey, M., Slagle, B.L., McArthur, M.J., Montogomery, Jr. C.A., Butel, J.S., Bradley A. (1992). Mice deficient for p53 are developmentally normal but susceptible to spontaneous tumours. Nature, 356, 215-221

Dualan, R., Brody, T., Keeney, S., Nichols, A.F., Admon, A., Linn, S. (1995). Chromosomal localization and cDNA cloning of the genes (DDB1 and DDB2) for the p127 and p48 subunits of a human damage specific DNA-binding protein. Genomics, 29, 62-69

El-Mahdy, M.A., Zhu, Q., Wang, Q.E., Wani, G., Praetorius-Ibba, M., Wani, A.A. (2006). Cullin 4A-mediated proteolysis of DDB2 protein at DNA damage sites regulates in vivo lesion recognition by XPC. J. Biol. Chem., 281: 13404-13411

Feldberg, R.S., Grossman, L. (1976). A DNA binding protein from human placenta specific for ultraviolet damaged DNA. Biochemistry, 15, 2402-2408 
Fitch, M.E., Nakajima, S., Yasui, A., Ford, J.M. (2003). In vivo recruitment of XPC to UVinduced cyclobutane pyrimidine dimers by the DDB2 gene product. J. Biol. Chem., 278, 46906-46910

Friedberg, E.C., Walker, G.C., Siede, W., Wood, R.D., Schultz, R.A., Ellenberger, T. (2006). DNA repair and mutagenesis. Second Edition, ASM Press, Washington, DC

Fujiwara, Y., Masutani, C., Mizukoshi, T., Kondo, J., Hanaoka, F., Iwai, S. (1999). Characterization of DNA recognition by the human UV-damaged DNA-binding protein. J. Biol. Chem., 274, 20027-20033

Gonzalez, V.M., Fuertes, M.A., Alonso, C., Perez, J.M. (2001). Is cisplatin-induced cell death always produced by apoptosis? Mol. Pharmacol., 59, 657-663

Groisman, R., Polanowska, J., Kuraoka, I., Sawada, J., Saijo, M., Drapkin, R., Kisselev, A.F., Tanaka, K., Nakatani, Y. (2003). CSA complexes is differentially regulated by the COP9 signalosome in response to DNA damage. Cell, 113, 357-367

Guerrero-Santoro, J., Kapetanaki, M.G., Hsieh, C.L., Gorbachinsky, I., Levine, A.S., RapicOtrin, V. (2008). The cullin 4B-based UV-damaged DNA-binding protein ligase binds to UV-damaged chromatin and ubiquitinates histone H2A. Cancer Res., 68, 5014-5022

Hayes, S., Shiyanov, P., Chen, X., Raychaudhuri, P. (1998). DDB, a putative DNA repair protein, can function as a transcriptional partner of E2F1. Mol. Cell Biol.,18, 240-249

Higa, L.A., Mihaylov, I.S., Banks, D.P., Zheng, J., Zhang, H. (2003). Radiation-mediated proteolysis of CDT1 by CUL4-ROC1 and CSN complexes constitutes a new checkpoint. Nat. Cell Biol., 5, 1008-1015

Hu, J., McCall, C.M., Ohta, T., Xiong, Y. (2004). Targeted ubiquitination of CDT1 by the DDB1-CUL4A-ROC1 ligase in response to DNA damage. Nat. Cell Biol., 6, 10031009

Hwang, B.J., Ford, J.M., Hanawalt, P.C., Chu, G. (1999). Expression of the p48 xeroderma pigmentosum gene is p53-dependent and is involved in global genomic repair. Proc. Natl. Acad. Sci. U.S.A., 96, 424-428

Inoki, T., Yamagami, S., Inoki, Y., Tsuru, T., Hamamoto, T., Kagawa, Y., Mori, T., Endo, H. (2004). Human DDB2 splicing variants are dominant negative inhibitors of UVdamaged DNA repair. Biochem. Biophys. Res. Commun., 314, 1036-1043

Itoh, T., Linn, S., Ono, T., Yamaizumi, M. (2000). Reinvestigation of the classification of five cell strains of xeroderma pigmentosum group E with reclassification of three of them. J. Invest. Dermatol., 114,1022-1029

Itoh, T., O'Shea, C., Linn, S. (2003). Impaired regulation of tumor suppressor p53 caused by mutations in the xeroderma pigmentosum DDB2 gene: mutual regulatory interactions between p48 DDB2 and p53. Mol. Cell. Biol., 23, 7540-7553

Itoh, T., Cado, D., Kamide, Y., Linn, S. (2004). DDB2 disruption leads to skin tumors and resistance to apoptosis after exposure to ultraviolet light but not a chemical carcinogen. Proc. Natl. Acad. Sci. USA, 101, 2052-2057

Itoh, T. (2006). Xeroderma pigmentosum group E and DDB2, a smaller subunit of damagespecific DNA binding protein: Proposed classification of xeroderma pigmentosum, Cockayne syndrome, and ultraviolet-sensitive syndrome. .J Dermatol. Sc.i, 41, 87-96

Jacks, T., Remington, L., Williams, B.O., Schmitt, E.M., Halachmi, S., Bronson, R.T., Weinberg, R.A. (1994).Tumor spectrum analysis in p53-mutant mice. Curr Biol, 4,1-7 
Jackson, S., Xiong, Y. (2009). CRL4s: the CUL4-RING E3 ubiquitin ligases. Trends Bochem. Sci., 34, 562-570

Kamarajan, P., Sun, N.-K., Chao, C.C.-K. (2003). Upregulation of FLIP in cisplatin-selected HeLa cells causes cross-resistance to Fas death signaling. Biochem. J., 376, 253-260

Kapetanaki, M.G., Guerrero-Santoro, J., Bisi, D.C., Hsieh, C.L., Rapic-Otrin, V., Levine, A.S. (2006). The DDB1-CUL4ADDB2 ubiquitin ligase is deficient in xeroderma pigmentosum group $\mathrm{E}$ and targets histone H2A at UV-damaged DNA sites. Proc. Natl. Acad. Sci. U.S.A., 103, 2588-2593

Keeney, S., Chang, G.J., Linn, S. (1993). Characterization of a human DNA damage binding protein implicated in xeroderma pigmentosum E. J. Biol. Chem., 268, 21293-21300.

Keeney, S., Eker, A.P.M., Brody, T., Vermeulen, W., Bootsma, D., Hoeijmakers, J.H.J., Linn, S. (1994). Correction of the DNA repair defect in xeroderma pigmentosum group $\mathrm{E}$ by injection of a DNA damage binding protein. Proc. Natl. Acad. Sci. U.S.A., 91, 4053-4056

Kemp, C.J., Donehower, L.A., Bradley, A., Balmain, A. (1993). Reduction of p53 gene dosage does not increase initiation or promotion but enhances malignant progression of chemically induced skin tumors. Cell, 74, 813-822

Kulaksiz, G., Reardon, J.T., Sancar, A. (2005). Xeroderma pigmentosum complementation group $\mathrm{E}$ protein (XPE/DDB2): purification of various complexes of XPE and analyses of their damaged DNA binding and putative DNA repair properties. Mol. Cell. Biol., 25, 9784-9792

Lee, J., Zhou, P. (2007). DCAFs, the missing link of the CUL4-DDB1 ubiquitin ligase. Molecular Cell, 26, 775-780

Lee, T.H., Elledge, S.J., Butel, J.S. (1995). Hepatitis B virus X protein interacts with a probable cellular DNA repair protein., J. Virol., 69, 1107-1114

Lin-Chao, S., Chao, C.C.-K. (1994). Reduced inhibition of DNA synthesis and $\mathrm{G}_{2}$ arrest in the cell cycle progression of resistant HeLa cells in response to cisdiamminedichloroplatinum(II). J. Biomed. Sci., 1, 131-138

Mitchell, D.L., Haipek, C.A., Clarkson, J.M. (1985). (6-4) Photoproducts are removed from the DNA of UV-irradiated mammalian cells more efficiently than cyclobutane pyrimidine dimers. Mutat. Res., 143, 109-112

Moser, J., Volker, M., Kool, H., Alekseev, S., Vrieling, H., Yasui, A., van Zeeland, A.A., Mullenders, L.H. (2005). The UV-damaged DNA binding protein mediates efficient targeting of the nucleotide excision repair complex to UV-induced photo lesions. DNA Repair, 4, 571-582

Nakane, H., Takeuchi, S., Yuba, S., Siajo, M., Nakatsu, Y., Murai, H., Nakatsuru, Y., Ishikawa, T., Hirota, S., Kitamura, Y., Kato, Y., Tsunoda, Y., Miyauchi, H., Horio, T., Tokunaga, T., Matsunaga, T., Nikaido, O., Nishimune, Y., Okada a, Y., Tanaka, K. (1995). High incidence of ultraviolet-B- or chemical-carcinogen induced skin tumours in mice lacking the xeroderma pigmentosum group A gene. Nature, 377,165-168

Nichols, A.F., Ong, P., Linn, S., (1996). Mutations specific to the xeroderma pigmentosum group-E DDB(-) phenotype. J. Biol. Chem., 271, 24317-24320

Nichols, A.F., Itoh, T., Graham, J.A., Liu, W., Yamaizumi, M., Linn, S. (2000). Human damage-specific DNA-binding protein p48: characterization of XPE mutations and regulation following UV irradiation. J. Biol. Chem., 275, 21422-21428 
Payne, A., Chu, G., (1994). Xeroderma pigmentosum group E binding factor recognizes a broad spectrum of DNA damage. Mutat. Res., 310, 89-102

Peng, K.-Y. (2008). Effects of DDB2 overexpression on UV toxicity and cell growth. Master thesis, Chang Gung University, Taiwan

Phillips, A.C., Ernst, M.K., Bates, S., Rice, N.R., Vousden, K.H. (1999). E2F-1 potentiates cell death by blocking antiapoptotic signaling pathways. Mol. Cell 4, 771-781

Rapic-Otrin, V., McLenigan, M.P., Bisi, D.C., Gonzalez, M., Levine, A.S. (2002). Sequential binding of UV DNA damage binding factor and degradation of the p48 subunit as early events after UV irradiation. Nucleic Acids Res., 30, 2588-2598

Scrima, A., Konickova, R., Czyzewski, B.K., Kawasaki, Y., Jeffrey, P.D., Nakatani, R.Y., Iwai, S., Pavletich, N.P., Thoma, N.H. (2008). Structural basis of UV DNA damage recognition by the DDB1-DDB2 complex. Cell, 135, 1213-1223

Shiyanov, P., Hayes, S.A., Donepudi, M., Nichols, A.F., Linn, S., Slagle, B.L., Raychaudhuri, P. (1999).The naturally occurring mutants of DDB are impaired in stimulating nuclear import of the p125 subunit and E2F1-activated transcription. Mol. Cell Biol., $19,4935-4943$

Stanelle, J., Stiewe, T., Theseling, C.C., Peter, M., Putzer, B.M. (2002). Gene expression changes in response to E2F1 activation. Nucleic Acids Res., 30,1859-1867

Stoyanova, T., Roy, N., Kopanja, D., Bagchi, S., Raychaudhuri, P. (2009). DDB2 decides cell fate following DNA damage. Proc Natl Acad Sci USA, 106, 10690-10695

Sugasawa, K., Ng, J.M., Masutani, C., Iwai, S., van der Spek, P.J., Eker, A.P., Hanaoka, F., Bootsma, D., and Hoeijmakers, J.H. (1998). Xeroderma pigmentosum group C protein complex is the initiator of global genome nucleotide excision repair. Mol. Cell, 2, 223-232

Sugasawa, K., Okuda, Y., Saijo, M., Nishi, R., Matsuda, N., Chu, G., Mori, T., Iwai, S., Tanaka, K., Tanaka, K., Hanaoka, F. (2005). UV-induced ubiquitylation of XPC protein mediated by UV-DDB-ubiquitin ligase complex. Cell, 121, 387-400

Sugasawa, K. (2009). UV-DDB: A molecular machine linking DNA repair with ubiquitination. DNA Repair, 8, 969-972

Sugasawa, K. (2010). Regulation of damage recognition in mammalian global genomic nucleotide excision repair. Mutat. Res., 685, 29-37

Sun, C.-L., Chao, C.C.-K. (2005a). Cross-resistance to death ligand-induced apoptosis, in cisplatin-selected HeLa cells, associated with overexpression of DDB2 and subsequent induction of cFLIP. Mol. Pharmacol., 67, 1307-1314

Sun, C.-L., Chao, C.C.-K. (2005b). Potential attenuation of p38 signaling by DDB2 as a factor in acquired TNF resistance. Int. J. Cancer, 115, 383-389

Sun, N.-K., Kamarajan, P., Huang, H., Chao, C.C.-K. (2002a). Restoration of UV sensitivity in UV-resistant HeLa cells by antisense-mediated depletion of damaged DNAbinding protein 2 (DDB2). FEBS Lett., 512, 168-172

Sun, N.-K., Lu, H.-P., Chao, C.C.-K. (2002b). Overexpression of damaged DNA-binding protein 2 (DDB2) potentiates UV resistance in hamster V79 cells. Chang Gung Med. J., 25, 686-695

Sun, N.-K., Sun, C.-L., Lin, C.-H., Pai, L.-M., Chao, C.C.-K. (2010). Damaged DNA-binding protein 2 (DDB2) protects against UV irradiation in human cells and Drosophila. J. Biomed. Sci., 17, 27 
Takao, M., Abramic, M., Moos, M., Otrin, V.R., Wootton, J.C., McLenigan, M., Levine, A.S., Protic', M. (1993). A 127 kDa component of a UV-damaged DNA-binding complex, which is defective in some xeroderma pigmentosum group $\mathrm{E}$ patients, is homologous to a slime-mold protein, Nucleic Acids Res. 21 (1993) 4111-4118.

Tang, J.Y., Hwang, B.J., Ford, J.M., Hanawalt, P.C., Chu, G. (2000). Xeroderma pigmentosum p48 gene enhances global genomic repair and suppresses UV-induced mutagenesis. Mol. Cell, 5, 737-744

Tang, J., Chu, G. (2002). Xeroderma pigmentosum complementation group E and UVdamaged DNA-binding protein. DNA Repair, 1, 601-616

de Vries, A., van Oostrom, C.T.M., Hofhuis, F.M.A., Dortant, P.M., Berg, R.J.W., de Gruiji, F.R., Wester, P.W., van Kreijl, C.F., Capel, P.J., van Steeg, H., Verbeek, S.J. (1995). Increased susceptibility to ultraviolet-B and carcinogens of mice lacking the DNA excision repair gene XPA. Nature 377, 169-173

Wang, H., Zhai, L., Xu, J., Joo, H.-Y., Jackson, S., Erdjument-Bromage, H., Tempst, P., Xiong, Y., Zhang, Y. (2006). Histone H3 and H4 ubiquitylation by the CUL4-DDB-ROC1 ubiquitin ligase facilitates cellular response to DNA damage. Mol. Cell, 22, 383-394

Wittschieben, B.O., Iwai, S., Wood, R.D. (2005). DDB1-DDB2 (xeroderma pigmentosum group E) protein complex recognizes a cyclobutane pyrimidine dimer, mismatches, apurinic/apyrimidinic sites, and compound lesions in DNA. J. Biol. Chem., 280, 39982-39989 


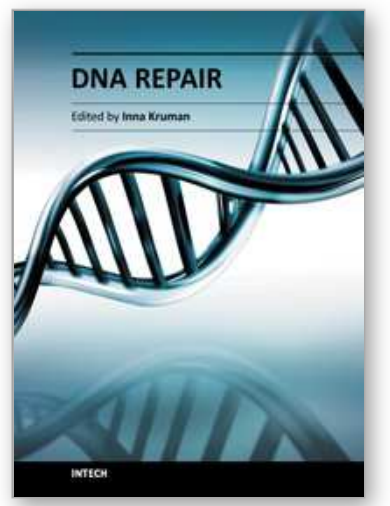

\author{
DNA Repair \\ Edited by Dr. Inna Kruman
}

ISBN 978-953-307-697-3

Hard cover, 636 pages

Publisher InTech

Published online 07, November, 2011

Published in print edition November, 2011

The book consists of 31 chapters, divided into six parts. Each chapter is written by one or several experts in the corresponding area. The scope of the book varies from the DNA damage response and DNA repair mechanisms to evolutionary aspects of DNA repair, providing a snapshot of current understanding of the DNA repair processes. A collection of articles presented by active and laboratory-based investigators provides a clear understanding of the recent advances in the field of DNA repair.

\title{
How to reference
}

In order to correctly reference this scholarly work, feel free to copy and paste the following:

Chuck C.-K. Chao (2011). The Role of DDB2 in Regulating Cell Survival and Apoptosis Following DNA Damage - A Mini-Review, DNA Repair, Dr. Inna Kruman (Ed.), ISBN: 978-953-307-697-3, InTech, Available from: http://www.intechopen.com/books/dna-repair/the-role-of-ddb2-in-regulating-cell-survival-and-apoptosisfollowing-dna-damage-a-mini-review

\section{INTECH}

open science | open minds

\section{InTech Europe}

University Campus STeP Ri

Slavka Krautzeka 83/A

51000 Rijeka, Croatia

Phone: +385 (51) 770447

Fax: +385 (51) 686166

www.intechopen.com

\section{InTech China}

Unit 405, Office Block, Hotel Equatorial Shanghai

No.65, Yan An Road (West), Shanghai, 200040, China

中国上海市延安西路65号上海国际贵都大饭店办公楼 405 单元

Phone: +86-21-62489820

Fax: $+86-21-62489821$ 
(C) 2011 The Author(s). Licensee IntechOpen. This is an open access article distributed under the terms of the Creative Commons Attribution 3.0 License, which permits unrestricted use, distribution, and reproduction in any medium, provided the original work is properly cited. 